\title{
FUNCTIONAL OUTCOME AFTER EXPERIMENTAL CAUDA EQUINA COMPRESSION
}

\author{
FARES E. SAYEGH, GEORGE A. KAPETANOS, PAN P. SYMEONIDES, GEORGE ANOGIANNAKIS, \\ MINAS MADENTZIDIS
}

From the Aristotelian University of Thessaloniki, Greece

Spinal nerve roots often sustain compression injuries. We used a Wistar rat model of the cauda equina syndrome to investigate such injuries. Rapid transient compression of the cauda equina was produced using a balloon catheter. The results were assessed by daily neurological examination and somatosensory evoked potential (SEP) recording before surgery and ten weeks after decompression.

Compression of the spinal nerves induced changes in the SEP which persisted for up to ten weeks after decompression, but it had no effect on the final neurological outcome. Our study shows the importance of early surgical decompression for cauda equina syndrome.

J Bone Joint Surg [Br] 1997;79-B:670-4.

Received 2 July 1996; Accepted after revision 31 October 1996

The spinal nerve roots of the cauda equina may sustain compression injuries which are either chronic due to disc prolapse and spinal stenosis, or acute after trauma.

The symptoms of cauda equina syndrome (CES) are low back pain, unilateral or bilateral sciatica and sensory disturbances in saddle distribution. Motor weakness of the lower limbs may progress to paralysis with bowel and bladder disturbances. CES has been considered to be the only absolute indication for surgical treatment of lumbar

F. E. Sayegh, MD, Orthopaedic Surgeon

G. A. Kapetanos, MD, Associate Professor

P. P. Symeonides, MD, Professor

Department of Orthopaedics

G. Anogiannakis, MD, Associate Professor

M. Madentzidis, MD, Assistant Professor

Department of Neurophysiology

Aristotelian University, Thessaloniki, Greece.

Correspondence should be sent to Dr G. A. Kapetanos at 8, Martiou Street, Panorama, Thessaloniki 55236, Greece.

(C)1997 British Editorial Society of Bone and Joint Surgery 0301-620X/97/47056\$2.00 disc disease, but the timing of such surgical intervention varies between spinal surgeons.

In 1959 Shephard ${ }^{1}$ suggested that early diagnosis and early surgical decompression were important for neurological recovery and the minimising of permanent neural damage. Kostuik et al $^{2}$ were unable to show any difference in motor and sensory function in patients with CES who had been operated on early or late, but recommended that decompression of the spinal nerves should be done as soon as possible. Jennett ${ }^{3}$ did not support early surgical intervention. O'Laoire, Crockard and Thomas ${ }^{4}$ found no correlation between the duration of symptoms and the results of treatment of CES and Delamarter, Sherman and Carr ${ }^{5}$ did not support the contention that decompression of CES was a surgical emergency.

We used a Wistar rat model for experimental compression of the spinal nerves of the cauda equina. We studied the recovery of neurological function in different groups after the rapid onset of compression injury to the cauda equina, and analysed the neurophysiological data obtained after full neurological recovery. Our aim was to determine the optimal time for surgical intervention.

\section{MATERIALS AND METHODS}

We used 52 adult female and male Wistar rats weighing between 250 and $380 \mathrm{~g}$. They were anaesthetised with $0.3 \mathrm{ml} / \mathrm{kg}$ of Fentanyl followed by $4 \mathrm{mg} / \mathrm{kg}$ of diazepam intraperitoneally. We performed partial left laminectomy at the level of the L5 to L6 intervertebral space through which a deflated arterial embolectomy balloon catheter (Dispo Medica GmBH, Hamburg, Germany; size 2F, inflated balloon diameter $4 \mathrm{~mm}$, maximum liquid capacity $0.05 \mathrm{ml}$ ) was passed and placed over the corresponding epidural space. The catheter was then connected to an inflation manometer device (Indeflator Plus; Advanced Cardiovascular Systems Inc, Temecula, California) which can create and monitor pressure in the balloon. The balloon catheter and the inflation manometer produced rapid compression of the cauda equina in less than $1 \mathrm{~s}$. The final maximum pressure applied within the balloon was $303 \mathrm{kPa}$ $(2250 \mathrm{mmHg})$ at $\leqslant 1 \mathrm{~s}$. A diluted radio-opaque medium was used to inflate the balloon and to check its position 
radiologically and the level of compression. The catheters were tested for their integrity before insertion through the laminectomy site.

Forty rats survived for the whole length of the experiment and were divided into five groups as follows:

Group 1. Twelve rats in which the cauda equina was compressed for $60 \mathrm{~min}$.

Group 2. Twelve rats with cauda equina compression for $30 \mathrm{~min}$.

Group 3. Six rats in a sham compression group had the balloon catheter inserted through the fenestration site and placed over the dura for $60 \mathrm{~min}$ without inflation.

Group 4. Six rats were treated as for group 3 but with exposure for only $30 \mathrm{~min}$.

Group 5. A control group of four rats had no surgery.

Neurological assessment. Neurological function was tested in all the animals before surgery and then daily for nine weeks after decompression. We used a modified test of the overall behavioural analysis of neurological function as described by Gale, Kerasidis and Wrathall. ${ }^{6}$ This included different evaluations of sensory and motor function. Points were assigned for abnormalities in function, so that a higher score indicated a greater functional deficit. The percentage functional deficit ranged from 0 for a completely normal rat to 100 for a rat that was completely anaesthetic and paralysed in the involved region. The combined behavioural score (CBS) of Gale et $\mathrm{al}^{6}$ is an index of the percentage of functional deficit (Table I).

Table I. The grading system of different tests and the percentage deficit assessed by the combined behavioural score $(\mathrm{CBS})^{*}$

\begin{tabular}{lll}
\hline Test & Grade & CBS \\
\hline Motor score & 0 & 5 \\
& 1 & 4 \\
& 2 & 3 \\
& 3 & 2 \\
Toe spread & 4 & 1 \\
Placing & 5 & 0 \\
Withdrawal & 0 or 1 & 1 \\
Inclined plane in degrees & 0 or 1 & 1 \\
& 0 or 1 & 1 \\
Climbing an edge $\dagger$ & $<30$ & 2 \\
& 35 to 50 & 1 \\
Standing on hindlimbs $\dagger$ & $>55$ & 0 \\
& 0 & 3 \\
Pathway crossing $\dagger$ & 1 & 2 \\
& 2 & 1 \\
& 3 & 0 \\
& 0 & 3 \\
& 1 & 2 \\
& 2 & 1 \\
& 3 & 0 \\
& 0 & 2 \\
& 1 & 1 \\
& 2 & 0 \\
& 0 & 2 \\
& 1 & 0 \\
\hline
\end{tabular}

* the CBS is the sum of the points for each test, maximum of 20 points; 20 points $\times 5=100 \%$ functional deficit $\dagger$ modified tests from the original analysis of Gale et al ${ }^{6}$
Neurophysiological recordings. We recorded somatosensory evoked potentials (SEP) before surgery on the control group and on another 18 rats from the remaining groups in the tenth postoperative week when they had fully recovered. We limited the SEP recordings to 18 experimental rats because of the consistency of the SEP waveforms produced. The control group was used to provide baseline values $(100 \%)$.

The recording and reference electrodes were placed in the skull and held with acrylic dental cement. A series of random electrical stimuli of intensity $1.5 \mathrm{~V}$, mean frequency $2 \mathrm{~Hz}$ and duration $0.2 \mathrm{~ms}$, was generated by a stimulator connected to a single-phase current (IS/V by Medelec Ltd, Old Woking, UK). The stimuli were delivered to a bipolar nerve-stimulating electrode (DISA, Hezlev, Denmark) placed subcutaneously along the right superficial peroneal nerve. The voltage intensity used to stimulate the nerve was adjusted to just below the motor threshold, i.e., the voltage at which the limb no longer twitched during stimulation. We used a Medelec 3000 digital averager to perform, analyse and monitor the SEP signals. An average waveform of 128 single sweeps was used. The SEP signals which were identified in all groups had the N-P waveform pattern. We analysed the SEP waveforms according to de la Torre and Boggan ${ }^{7}$ and Manil et al $^{8}$ in which the earliest positive cortical peak was designated as P1 and the earliest negative peak as N1. Six major peaks were identified in most of the rats: three positive peaks described as P1, P2 and P3, according to the order of their appearance, and three negative peaks N1, N2 and N3. Late peaks were not used because of their inconsistency. The values of the latencies of peaks in all groups were expressed in milliseconds. The N2-P2 amplitude complex, the most consistent and reproducible component of the SEP pattern, was expressed as a percentage when compared with the baseline value $(100 \%)$ of the control group. The values of the latencies of peaks in all groups were expressed in milliseconds. The N2-P2 amplitude complex, the most consistent and reproducible component of the SEP pattern, was expressed as a percentage of the baseline value (100\%) of the control group.

Statistical analysis. We used the Kruskal-Wallis and the Mann-Whitney (Wilcoxon) W tests as non-parametric methods to analyse the available data.

\section{RESULTS}

Neurological function. All the animals completely regained their normal preoperative neurological function and none had complete paralysis of the hindlimbs after compression of the spinal nerves. In groups 1 and 2 the period of time for complete recovery was nine and eight weeks, respectively and statistical analysis showed no difference in recovery $(0.08 \leqslant \mathrm{p} \leqslant 0.24)$.

Groups 3 and 4 in which the cauda equina had not been 
Table II. Samples of the results of behavioural analysis of the left hindlimb after decompression

\begin{tabular}{|c|c|c|c|c|c|c|c|c|c|c|c|}
\hline & \multicolumn{3}{|c|}{ Group 1 (weeks) } & \multicolumn{3}{|c|}{ Group 2 (weeks) } & \multicolumn{3}{|c|}{ Group 3 (weeks) } & \multicolumn{2}{|c|}{ Group 4 (weeks) } \\
\hline & 1 & 3 & 7 & 1 & 3 & 7 & 1 & 3 & 7 & 1 & 3 \\
\hline Motor score & 3.15 & 2 & 0.4 & 2.7 & 1.5 & 0.2 & 1.76 & 0.46 & 0 & 0.6 & 0 \\
\hline Toe spread & 1 & 1 & 0 & 1 & 1 & 0 & 1 & 0.1 & 0 & 0 & 0 \\
\hline Placing & 1 & 1 & 0 & 1 & 0.74 & 0 & 0.9 & 0.07 & 0 & 0 & 0 \\
\hline Withdrawal & 1 & 0.64 & 0 & 1 & 0.46 & 0 & 0.9 & 0.16 & 0 & 0 & 0 \\
\hline Inclined plane & 1 & 1 & 0.05 & 1 & 1 & 0 & 1 & 0.1 & 0 & 0.2 & 0 \\
\hline Climbing & 2.8 & 2.1 & 0.6 & 2.2 & 1.4 & 0.02 & 1.6 & 0.5 & 0 & 0.5 & 0 \\
\hline Standing & 2.9 & 2 & 0.3 & 2.1 & 1.3 & 0.1 & 1.5 & 0.7 & 0 & 0.5 & 0 \\
\hline Tail & 2.3 & 1.3 & 0.08 & 2.2 & 1.1 & 0 & 1.5 & 0.4 & 0 & 0.4 & 0 \\
\hline Pathway & 1.4 & 1 & 0 & 1.1 & 0.3 & 0 & 0 & 0 & 0 & 0 & 0 \\
\hline
\end{tabular}

Table III. Samples of the percentage functional deficit of both hind limbs

\begin{tabular}{|c|c|c|c|c|c|c|c|c|}
\hline \multirow[b]{2}{*}{ Week } & \multicolumn{2}{|c|}{ Group 1} & \multicolumn{2}{|c|}{ Group 2} & \multicolumn{2}{|c|}{ Group 3} & \multicolumn{2}{|c|}{ Group 4} \\
\hline & Left & Right & Left & Right & Left & Right & Left & Right \\
\hline 1 & 82.8 & 81.0 & 71.5 & 70.0 & 50.8 & 42.4 & 11.0 & 9.1 \\
\hline 4 & 47.9 & 38.4 & 29.5 & 25.1 & 3.3 & 2.45 & 0.0 & 0.0 \\
\hline 7 & 7.15 & 6.4 & 1.6 & 0.6 & 0.0 & 0.0 & & \\
\hline 9 & 0.0 & 0.0 & 0.0 & 0.0 & & & & \\
\hline
\end{tabular}

compressed by the balloon catheter represented spinal canal stenosis. The period of time for complete recovery in both groups was six and three weeks, respectively (Table II) which was a statistically highly significant difference $(p<0.005)$. The percentage functional deficit of the left hindlimb was always greater than that of the right and had a longer recovery time (Table III), and statistically showed no difference $(0.1 \leqslant \mathrm{p} \leqslant 0.5)$.

Neurophysiological recordings. The average peak-topeak latency (N1 to N3) of group 5 (control) was $31.67 \pm$ 0.22 (SD) ms. In group 1 it was $39.5 \pm 0.70 \mathrm{~ms}$, in group 2, $38.45 \pm 0.62 \mathrm{~ms}$, in group 3, $32.1 \pm 0.3 \mathrm{~ms}$ and in group 4 , $31.9 \pm 0.1 \mathrm{~ms}$ (Fig. 1). All the peak-to-peak latencies of groups 1 and 2 differed statistically from those from all the other groups $(\mathrm{p}<0.05)$. The peak-to-peak latencies of groups 3,4 and 5 showed no significant differences $(0.1 \leqslant \mathrm{p} \leqslant 0.37)$.

The N2 to P2 amplitude was more consistent and reliable than the N1 to P1 and the N3 to P3 complexes and was measured in all groups. In group 1 the decrease in the N2 to P2 amplitude was $65.7 \pm 0.82 \%$, in group 2 it was $30.7 \pm$ $2.13 \%$, and in groups 3 and 4 there was no decrease ten weeks after decompression as compared with the control group.

\section{DISCUSSION}

Tandon and Sankaran as quoted in Delamarter et $\mathrm{al}^{5}$ described three variations of the CES: acute CES accompanied by sudden motor and sensory disturbances of the lower limbs with no previous history of low back problems; acute bladder dysfunction with a history of low back pain and sciatica; and chronic low back pain with symptoms that gradually progressed to CES.

In our study, groups 1 and 2 represented acute CES and groups 3 and 4 simulated spinal canal stenosis. The stimulation of spinal stenosis can be explained on the basis of the anatomy of the lumbar vertebral canal in rats ${ }^{9}$; the spinal canal at the level L5 to L6 decreases from 3 to $2 \mathrm{~mm}$ caudally and it is further narrowed with the introduction of the deflated balloon catheter (diameter $1.1 \mathrm{~mm}$ ).

The most common aetiology of CES in man is prolapse of a lumbar disc but there is no detailed information about the pressure acting on the nerve roots. Charnley ${ }^{10}$ and Hendry ${ }^{11}$ found in studies in vitro that the swelling pressure of the nucleus pulposus, when exposed to water within a confined space, may exceed several hundred millimetres of mercury. In our study we used a similar high balloon pressure to compress the spinal nerve roots of groups 1 and 2. The magnitude of this pressure was higher than all critical pressure levels in other similar experiments and had a faster rate of onset. Olmarker et $\mathrm{al}^{12}$ and Olmarker ${ }^{13}$ found that a rapid onset rate of compression $(0.05$ to $0.1 \mathrm{~s})$ induced more pronounced effects than a slower onset rate (20 s).

The time required for the hindlimbs of the animals of groups 1 and 2 to regain their full neurological function was longer than that of groups 3 and 4 . Compression may induce the formation of oedema in peripheral nerve tissue ${ }^{14}$ and dorsal root ganglia ${ }^{15}$ and this time difference in recovery may be due to greater intraneural oedema after the rapid onset of compression. Endoneural oedema may be induced after compression at either $50 \mathrm{mmHg}$ for four to six hours or at $200 \mathrm{mmHg}$ for two hours. ${ }^{16}$ The formation of oedema was more pronounced in the groups with rapid compression than in the sham-operated groups in which the balloon 
catheter was lying over the nerve roots without compression. $^{12}$

The duration of compression of the nerve tissue also plays a significant role in the degree of oedema formation. ${ }^{13}$ In our study the longer duration of compression of the cauda equina in group 1 extended the time required for these animals to recover completely.

The SEP of groups 1 and 2 at ten weeks after decompression did not correlate with the clinical function of the hindlimbs. The rats recovered fully but there was an aver-

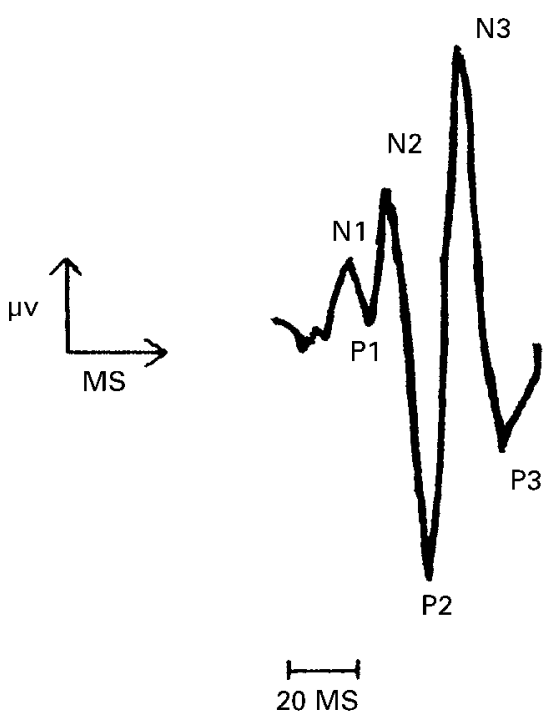

Group 2

(30 min compression)

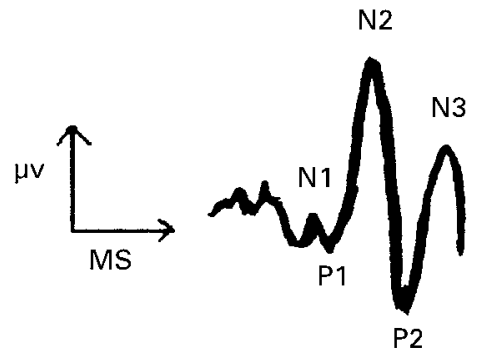

$20 \mathrm{MS}$

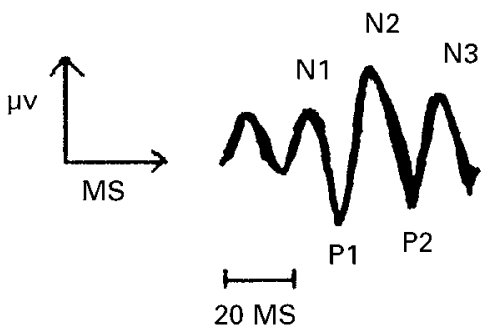

Group 1

(60 min compression) age decrease in the amplitude of the SEP in group 1 of $65.84 \pm 0.74 \%$ and in group 2 of $32.1 \pm 2.09 \%$. In addition, the latencies of groups 1 and 2 were prolonged as compared with those of the control group. This reduction of amplitude and the prolonged latency may be due to impairment of nerve conduction as a result of the rapid onset of compression. During prolonged compression periods, more pronounced oedema may affect a wider nerve-root segment. ${ }^{13}$

Long-standing oedema may be related to the formation of an intraneural fibrotic scar ${ }^{14}$ which may contribute to the slow clinical recovery as well as to reduction in mean amplitudes and prolonged latencies in the compression groups 1 and 2 .

When spinal nerve injury is due to spinal stenosis, as simulated in groups 3 and 4, complete neurological and neurophysiological recovery should be achieved after surgical decompression. The timing of decompression is not important since recovery is complete after either early or Normal late decompression (groups 4 and 3, respectively). In acute compression injuries of the cauda equina in which there is significant displacement and mechanical deformation of the spinal nerves (groups 1 and 2) clinical recovery was delayed but was complete, although the SEP did not recover completely (Fig. 1). The timing of decompression is important in such cases because recovery of the SEP was evident after earlier decompression of the cauda equina (group 2) and was minimal when surgical intervention was delayed (group 1).
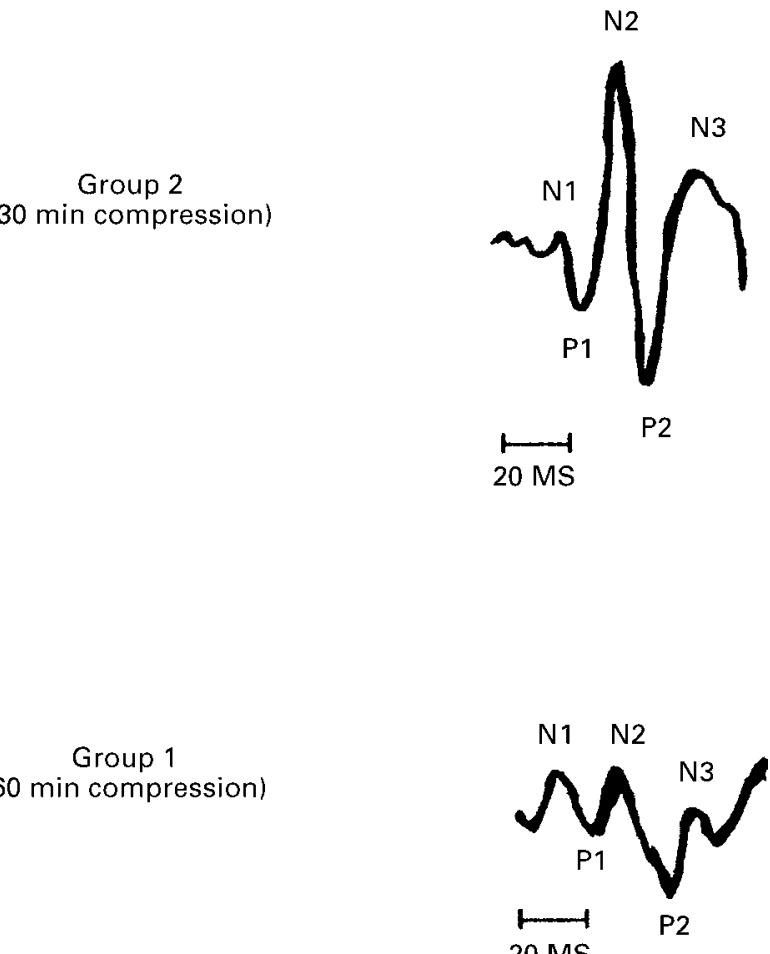

Fig. 1 
No benefits in any form have been received or will be received from a commercial party related directly or indirectly to the subject of this article.

\section{REFERENCES}

1. Shephard RH. Diagnosis and prognosis of cauda equina syndrome produced by protrusion of lumbar disk. Br Med J 1959;2:1434-9.

2. Kostuik JP, Harrington I, Alexander D, et al. Cauda equina syndrome and lumbar disc herniation. J Bone Joint Surg [Am] 1986; 68-A:386-91.

3. Jennett WB. A study of 25 cases of compression of the cauda equina by prolapsed intervertebral discs. I Neurol Neurosurg Psychiat 1956; 19:109-16.

4. O'Laoire SA, Crockard HA, Thomas DG. Prognosis for sphincter recovery after operation for cauda equina compression owing to lumbar disc prolapse. Br Med J Clin Res Ed 1981;282:1852-4.

5. Delamarter RB, Sherman JE, Carr JB. Cauda equina syndrome: neurologic recovery following immediate, early, or late decompression. Spine 1991;16:1022-9.

6. Gale K, Kerasidis H, Wrathall JR. Spine cord contusion in the rat: behavioural analysis of functional neurologic impairment. Exp Neurol 1985;88:123-34.

7. de la Torre JC, Boggan JE. Neurophysiological recording in rat spinal cord trauma. Exp Neurol 1980;70:356-70.
8. Manil J, Colin F, Capon A, Deltenre P, Van Nechel Ch. Effects of specific spinal cord lesions on cortical somatosensory evoked potentials in the non-anaesthetised rabbit: evoked potentials. Proceedings of an international evoked potentials symposium held in Nottingham, England, 1980:401-6.

9. Hebel R, Stromberg MW. Anatomy of the laboratory rat. Baltimore: William and Wilkins Company, 1976;11:119-20.

10. Charnley J. The imbibition of fluid as a cause of herniation of the nucleus pulposus. Lancet 1952;1:124-7.

11. Hendry NGC. The hydration of the nucleus pulposus and its relation to intervertebral disc derangement. J Bone Joint Surg [Br] 1958;40-B: 132-44.

12. Olmarker K, Rydevik B, Holm S, Bagge U. Effects of experimental, graded compression on blood flow in spinal nerve roots: a vital microscopic study on the porcine cauda equina. J Orthop Res 1989;7: 817-23.

13. Olmarker G. Spinal nerve root compression: nutrition and function of the porcine cauda equina compressed in vivo. Acta Orthop Scand 1991;242:62:1-27.

14. Rydevik B, Brown MD, Lundborg G. Pathoanatomy and pathophysiology of nerve root compression. Spine 1984;9:7-15.

15. Rydevik BL, Myers RR, Powell HC. Pressure increase in dorsal root ganglion following mechanical compression: closed compartment syndrome in nerve roots. Spine 1989;14:574-6.

16. Rydevik BL, Pedowitz RA, Hargens AR, et al. Effects of acute, graded compression on spinal nerve root function and structure: an experimental study of the pig cauda equina. Spine 1991;16:487-93. 